\title{
Emergency contraception moves behind the counter
}

$\mathrm{H}$

ealth Canada's reclassification of the levonorgestrel "morning-after pill" as a nonprescription drug, thus permitting pharmacists to dispense this postcoital oral contraceptive directly to women who need it, when they need it, is welcome news (see page 861). ${ }^{1}$ Less welcome is the "behind the counter" classification of levonorgestrel $0.75 \mathrm{mg}$ (Plan B) by the provinces, which makes consultation with a pharmacist mandatory for any woman seeking to avoid an unintended pregnancy in this way. Health Canada has supported this policy on the grounds that "pharmacists are well-positioned to play a major role in ... providing counselling about contraceptive options."

Not necessarily. Although pharmacists have front-line contact with patients and are equipped with professional guidelines for provision of emergency contraception, they are not ideally positioned for a counselling role in their typical practice settings. Few pharmacies offer the privacy necessary for such a conversation. This mundane fact, together with the professional fees attached to the consultation, represents a needless barrier to access.

Moreover, the need for professional consultation for oral emergency contraception is questionable. Levonorgestrel $0.75 \mathrm{mg}$ has been available in Canada by prescription since 2000. A first dose taken within 72 hours of unprotected intercourse, followed by a second 12 hours later, is highly effective in preventing ovulation, fertilization and implantation. There are no serious adverse effects to the woman or, if she happens already to be pregnant, to the fetus. Moreover, levonorgestrel satisfies all of the criteria for nonprescription status, including a long history of safe and effective use, low incidence of side effects (mainly mild nausea) and a simple and easily explained manner of use. Studies of self-administered oral emergency contraception have shown a high level of appropriate use without adverse effects. ${ }^{3,4}$ Why, then, must competent women who have experienced contraceptive failure, a lapse in caution, or sexual coercion or assault be regarded as fair game for unwanted questioning and unsought advice - at their own expense?

In 2001 over 106000 abortions were performed in
Canada; of these, 20000 were in women under 20 years of age. It is estimated that $40 \%-50 \%$ of pregnancies in Canada are unintended, despite the wide availability of contraceptive methods. One of the important barriers to the use of oral emergency contraception has been lack of timely access to a physician. Making the "morning-after pill" available in pharmacies without prescription is an important step forward.

Legislation in British Columbia, Saskatchewan and Quebec already allows pharmacists to dispense the drug without a physician's prescription; the drug's reclassification by Health Canada helps to equalize access to emergency contraception for women across the country. In this issue Judith Soon and colleagues ${ }^{5}$ (see page 878) report on the changes in emergency contraceptive uptake in $\mathrm{BC}$ over the period 1996 through 2002. They were particularly interested to see if nonprescription dispensing of emergency contraceptives by pharmacists in British Columbia (beginning in December 2000) was associated with an equivalent decrease in prescriptions written by physicians. This has not been the case. Prescriptions by physicians continued to increase, but were accompanied by a dramatic rise in total use resulting mainly from pharmacy dispensing. Thus there was a net gain in utilization. We can now expect a net decrease in abortion rates in British Columbia and nationwide. This is good news.

But the news would be better if a lingering paternalism in matters affecting women's reproductive health was not still hiding behind the counter. - CMAf

\section{References}

1. Sibbald B. Nonprescription status for emergency contraception. CMAJ 2005;172(7):861-2

2. Government of Canada. Regulations amending the food and drug regulations (1272 - levonorgestrel). C Gaz 2004; 138(21):1633-43. Available: www.hc-sc .gc.ca/hpfb-dgpsa/tpd-dpt/sch-1272_e.html (accessed 2005 Mar 3).

3. Glasier A, Baird D. The effects of self-administering emergency contraception. N Engl 7 Med 1998;339(1):1-4.

4. Raymond EG, Chen PL, Dalebout SM. "Actual use" study of emergency contraceptive pills provided in a simulated over-the-counter manner. Obstet Gynecol 2003;102(1):17-23.

5. Soon JA, Levine M, Osmond BL, Ensom MHH, Fielding DW. Effects of making emergency contraception available without a physician's prescription: a population-based study. CMA7 2005;172(7):878-83. 